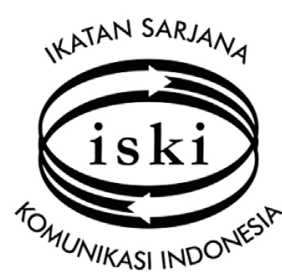

\section{POLITIK ETNISITAS DAN COMPLIANCE GAINING KANDIDAT MINORITAS DALAM PILKADA KALIMANTAN BARAT}

\author{
Zakina \\ Pascasarjana Departemen Ilmu Komunikasi \\ Universitas Indonesia \\ Jl. Salemba No. 4, Jakarta 10430 \\ zakina_suhor@yahoo.co.id
}

\begin{abstract}
Abstrak
Karakteristik masyarakat majemuk adalah adanya dominasi politik oleh suatu kelompok terhadap kelompokkelompok yang lain sehingga secara politik minoritas dikuasai oleh mayoritas. Namun, beberapa Kepala Daerah minoritas secara agama maupun etnis muncul sebagai sebagai pemenang. Diduga, cross cuttingaffiliation merupakan salah satu penyebab terpilihnya calon dari golongan minoritas. Pilkada Kalimantan Barat menjadi lokus penelitian ini dengan disain analisis deskriptif-eksplanasi melalui pendekatan studi kasus. Fokus pertanyaannya adalah bagaimana cross cutting affiliation secara agama dan etnis sebagai bagian dari politik etnisitas serta compliance gaining dalam pola dan strategi komunikasi digunakan pasangan kandidat terpilih pada Pilkada di Kalimantan Barat (Cornelis-Christiandy Sanjaya). Kesimpulannya: (1) Cornelis-Christiandy melakukan pendekatan modern dan tradisional; (2) Politik etnisitas Cornelis-Christiandy Sanjaya secara nonverbal melalui presentasi identitas seperti atribut, pakaian, dan simbol-simbol lainnya termasuk tempat tinggal dan komposisi warna yang paling dominan. Secara verbal melalui taktik presentasi asertif selama proses dialog dan debat berlangsung; (3) Cross cutting affiliation Cornelis-Christiandy Sanjaya sangat berperan dan mendukung dalam perolehan suara dari para pemilih di delapan Kota/Kabupaten, yaitu Landak, Sanggau, Sekadau, Melawi, Sintang, Singkawang, Kapuas Hulu, dan Bengkayang.
\end{abstract}

Kata Kunci: Politik Etnisitas, Minoritas, Compliance Gaining, Cross Cutting Affiliation.

\section{PENDAHULUAN}

Kemenangan pasangan Cornelis-Christiandy pada Pemilihan Kepala Daerah (Pilkada) Kalimantan Barat menambah daftar panjang kemenangan minoritas secara agama atau etnis di Indonesia. Pilkada Kalimantan Barat yang berlangsung 15 November 2007 telah mencatat Cornelis sebagai Gubernur Dayak pertama setelah tahun 1965. Sedangkan Wakil Gubernurnya, Christiandy berasal dari etnis Tionghoa. Mereka berdua adalah penganut agama minoritas: Cornelis, Katolik dan Christiandy Sanjaya beragama Protestan, sedangkan suku terbesar di Kalimantan, Dayak beragama mayoritas Islam.
Selain kemenangan dari pasangan dari agama minoritas tersebut, fenomena yang menarik dari Pilkada di Kalimantan Barat adalah proses Pilkada berlangsung secara damai dan lancar. Heterogenitas dan pluralisme yang dimiliki Kalimantan Barat ternyata mampu menjalankan Pilkada sebagaimana mestinya tanpa diwarnai konflik. Padahal beberapa tahun silam kerusuhan etnis sempat terjadi di propinsi ini dan menyisakan luka mendalam bagi semua lapisan masyarakat. Media massa membingkai kerusuhan antara etnis Dayak dan Madura di Kalimantan Barat sebagai potret buram kebhinekaan Indonesia dan ketakmampuan bertoleransi. Kalimantan Barat yang sempat identik dengan konflik 
etnis ternyata mampu menampilkan citra baru kematangan dalam berpolitik.

Sentimen etnis dalam pemilihan pejabat publik di Kalimantan Barat masih sangat kuat (Eriyanto, 2008:6). Hasil survei yang dilakukan April dan Mei 2007 oleh Lingkaran Survei Indonesia menunjukkan $56,4 \%$ responden memperhatikan latar belakang agama kandidat dan 44,3\% menjadikan etnis kandidat sebagai bahan pertimbangan penting. Sejarah pemerintahan di Kalimantan Barat turut mendukung fakta tersebut, karena hanya satu kali saja Kalbar dipimpin oleh Gubernur yang berasal dari suku Dayak pada masa Orde Lama. Setelah itu, kepimpinan Kalbar didominasi oleh Melayu dan Islam.

Lembaga Survei Indonesia (LSI) pimpinan Saiful Mujani, di awal Oktober 2007 atau satu bulan menjelang Pilkada juga mengindikasikan kenyataan serupa tentang tingginya dukungan suara terhadap pemimpin dari etnis Melayu dan Islam. Hasil survey menempatkan Usman Jafar pada urutan teratas dari calon-calon yang lain seperti Cornelis, Akil Mochtar, dan Oesman Sapta. Usman Jafar memperoleh 30,5\% suara sedangkan Cornelis 27\% suara.

Meskipun kutipan pernyataan yang diungkapkan oleh Ketua DPRD Kalbar, Ir. H. Zulfadhli kepada koran lokal Kalbar, Berkat bukanlah kesimpulan umum yang merujuk pada preferensi etnis dan agama dari semua lapisan masyarakat. Namun pernyataan ini dapat dijadikan bukti betapa kuatnya keinginan, baik secara individu maupun golongan untuk mempertahankan dominasi dari golongannya yang mungkin saja beragama Islam dan Melayu. Sebagai catatan, Usman Jafar sebelumnya terpilih sebagai Gubernur Kalbar bukan dari hasil Pilkada langsung tapi melalui legislatif (DPRD Kalbar). Berikut kutipan pernyataan tersebut (Harian Berkat, 1 Oktober 2007):

"Untuk itu saya mengimbau kepada semua jajaran pengurus, kader Partai Golkar Kalbar di semua lapisan wajib hukumnya untuk mensukseskan dan memenangkan pasangan calon Usman Ja'far-LH Kadir. Apabila ada pengurus, anggota legislatif Partai Golkar yang terlibat langsung maupun tidak langsung dengan memberikan dukungan terhadap calon lain maka akan dikenakan sanksi sesuai dengan mekanisme Partai Golkar bahkan akan diberikan sanksi terberat yaitu pemecatan."

Hitungan matematis dari LSI dan prediksi sejumlah pengamat ternyata berbeda dengan hasil
Pilkada. Sidang Pleno terbuka KPUD Kalbar di Gedung DPRD Kalimantan Barat pada tanggal 27 November 2007 akhirnya mengukuhkan CornelisChristiandy Sanjaya sebagai pemenang Pilkada dengan perolehan suara $43,67 \%$ (930.679 suara dari 2.131.089 suara sah). Kemenangan pasangan ini dinilai oleh pengamat politik Kalbar, Jumadi, sebagai hasil demokrasi politik Kalbar yang patut dibanggakan. "Khusus di Kalbar, pola politik yang berkembang sehingga menghasilkan pasangan Cornelis-Christiandy adalah politik identitas" (Kalimantan Review,150/XVII/Februari 2008). Pernyataan ini menguatkan asumsi bahwa identitas yang melekat pada diri pemenang pilkada (CornelisChristiandy), terutama etnis masih mempengaruhi pola perilaku pemilih Kalimantan Barat. Pemilih dari etnis Dayak tentunya akan memilih kandidat dari etnis Dayak, apalagi di daerah pemilihan yang basis etnisnya mayoritas Dayak.

Politik identitas terkait dengan etnisitas yang dimiliki seorang kandidat adalah suatu hal yang tidak bisa dihindari sebagai salah satu dampak dari pemilihan secara langsung. Buruknya, hal ini dikuatirkan akan menciptakan fragmentasi atau terkotak-kotaknya kondisi struktur sosial. Negaranegara besar dan maju seperti Amerika Serikat juga mengalami kondisi ini yang terkenal dengan sistem apartheidnya (pemisahan kulit hitam dan putih). Etnisitas yang dimiliki seseorang hanyalah suatu cara guna merujuk seperangkat tatacara, kebiasaan, adat-istiadat yang biasanya digunakan dalam kelompoknya bukan untuk politik. Namun tak dipungkiri bila rasa kedekatan emosional karena kesamaan etnis dengan kandidat yang dipilih berdampak pada tindakan politik seseorang seperti disampaikan Cohen (1996: 83): Ethnicity is essentially a political phenomenon, as traditional custom are used only as idiom, and as mechanisms for political alignment.

Etnisitas merupakan salah satu alternatif dari bentuk organisasi sosial dan identifikasi kelas sosial yang sifatnya kontingen dan bukan status yang dapat diubah sebagaimana halnya dengan kelas sosial, yang bisa atau tidak bisa ditekankan dalam konteks yang pasti atau waktu tertentu. Dalam kenyataannya seringkali komunitas etnis justru diciptakan dan diubah oleh elit politik tertentu dalam masyarakat yang modern untuk melakukan perubahan drama sosial melalui kompetisi dan konflik. Tujuannya adalah kekuasaan politik, keuntungan ekonomi, dan 
status sosial di antara elit politik yang bertarung. Bila hal ini dilakukan tentu saja fragmentasi sebagai salah satu dampak buruk politik identitas dapat terjadi. Tapi kalau hanya faktor kesamaan identitas (etnis dan agama) pemilih dengan kandidat sebagai suatu keputusan politik, bukanlah hal yang salah untuk dilakukan dan sah-sah saja adanya. Lebih spesifik tentang kaitan kelompok etnis dan formasi identitas etnis dalam politik, Paul R. Brass (dalam Hutchinson \& Smith, 1996:85) menyatakan pandangannya bahwa:

Ethnic groups that use ethnicity to make demands in the political arena for alteration in their status, in their economic well being, in their civil rights, or in their educational opportunities are engaged in a form of interest group politics which became prominent in the United Stated during the 1960s and 1970s and which sought to improve the well being of group members as individuals.

Kajian lebih lanjut tentang pengaruh etnis dan agama terhadap perilaku memilih di Indonesia menghasilkan dua versi pendapat. Pertama, Ananta (et.al) menyimpulkan di Indonesia secara relatif terdapat kesetiaan etnis (ethnic loyalty) yang relatif tinggi dan partai politik Indonesia dipengaruhi oleh etnisitas. Contohnya, wilayah dengan jumlah penduduk mayoritas Jawa memiliki kecenderungan untuk memilih PKB dan PDIP. Tabel 1.1 menunjukkan partai politik di Indonesia masih terbagi menurut dikotomi etnis serta Jawa dan luar Jawa.

Tabel 1.1

Partai Besar dan Sedang menurut Dukungan Etnis pada Pemilihan Umum 1999

\begin{tabular}{|l|l|l|}
\hline $\begin{array}{l}\text { Partai Besar/ } \\
\text { Sedang }\end{array}$ & Pemimpin & Dukungan Etnis \\
\hline PDI-P & Megawati & Jawa/Bali \\
\hline Golkar & $\begin{array}{l}\text { Habibie/Akbar } \\
\text { Tanjung }\end{array}$ & $\begin{array}{l}\text { Sumatera/Bugis/ } \\
\text { Makasar }\end{array}$ \\
\hline PKB & Gus Dur/Matori & Jawa \\
\hline PPP & Hamzah Haz & Etnis di Luar Jawa \\
\hline PAN & Amien Rais & Etnis di Luar Jawa \\
\hline PBB & Yusril Ihza Mahendra & Etnis di Luar Jawa \\
\hline
\end{tabular}

(Sumber: Ananta et.al, 2003:183)

Kedua, Liddle dan Mujani mengungkapkan hal sebaliknya bahwa aspek etnis bukanlah variabel penting dalam menjelaskan pilihan seseorang pada partai atau kandidat. Tidak ada perbedaan tegas pilihan seseorang pada partai atau kandidat berdasarkan pada etnis mereka sebagaimana yang disampaikan oleh Ananta (et.al) dalam temuannya. Pemilih yang berasal dari etnis Jawa atau Non Jawa tidak terlihat punya perbedaan pilihan partai atau kandidat presiden.

Argumentasi terhadap perbedaan temuan ini adalah karena perbedaan metode dan data yang digunakan (Eriyanto, 2008:2). Studi Ananta (et.al) menggunakan data agregat, dalam hal ini data etnis di masing-masing kabupaten/kota dari Badan Pusat Statistik (BPS) dan data perolehan suara di masingmasing kabupaten/kota dari Komisi Pemilihan Umum (KPU). Sedangkan Liddle dan Mujani menggunakan survei dengan sampel responden yang diambil secara representatif dan menggambarkan suara pemilih di Indonesia. Karena itu, penulis memiliki asumsi bahwa pengaruh etnis dan agama terhadap perilaku memilih dalam Pemilu maupun Pilkada sangatlah kontekstual pengaruhnya tergantung pada daerah dan karakteristik sosial budaya masyarakatnya. Pendapat ini diperkuat dengan munculnya pasangan pemenang Pilkada atau Kepala daerah yang berasal dari golongan minoritas secara etnis dan agama, ataupun minoritas secara etnis atau agama saja (termasuk Pilkada Kalbar). Beberapa contoh kepala daerah dari golongan minoritas ini dapat dilihat dalam tabel halaman berikut.

Kemenangan minoritas terhadap mayoritas dimungkinkan terjadi bila bertolak pada pandangan kaum Parsonian yang berpendapat bahwa masyarakat dianologikan sebagai sebuah sistem yang dibangun oleh sub-sub sistem. Jika terjadi ketegangan, penyimpangan, atau konflik dalam sistem tersebut maka kinerja sistem tersebut akan terganggu. Namun diasumsikan bahwa sistem tersebut selalu bergerak menuju titik keseimbangan, yang pada akhirnya akan mencapai integrasi. Diyakini oleh kaum Parsonian bahwa faktor cross cutting affiliation, yakni loyalitas ganda baik secara etnis maupun agama dapat menetralisir konflik antara kesatuan sosial dengan kesatuan sosial yang lain. Artinya, di satu sisi misalnya agama seseorang atau kandidat adalah minoritas, namun disisi lainnya (etnis) mayoritas atau sebaliknya. Minoritas dalam etnis namun mayoritas dalam agama.

\section{KERANGKA TEORITIS}

Etnisitas mempunyai berbagai perspektif (Tilaar, 2007:3). Dalam perspektif biologis, etnisitas menunjukkan sekelompok manusia yang 
Tabel 1.2

Minoritas Pemenang Pilkada

\begin{tabular}{|l|l|l|l|}
\hline $\begin{array}{l}\text { Kabupaten/ } \\
\text { Propinsi }\end{array}$ & $\begin{array}{l}\text { Pemenang/ } \\
\text { Kepala Daerah }\end{array}$ & $\begin{array}{l}\text { Mayoritas } \\
\text { (Agama dan Etnis) }\end{array}$ & $\begin{array}{l}\text { Keterangan } \\
\text { (Etnis dan Agama pemenang) }\end{array}$ \\
\hline Kabupaten Belitung Timur & Basuki Tjahaja Purnama & Melayu dan Islam & Tionghoa dan Protestan \\
\hline Kabupaten Simalungun & Zulkarnaen Damanik & Batak dan Kristen & Batak dan Islam \\
\hline Kalimantan Barat & Cornelis & Dayak dan Islam & Dayak dan Katolik \\
\hline Sulawesi Selatan & Sharul Yasin Limbo & Bugis dan Islam & Makasar dan Islam \\
\hline Murung Raya & Willy Yosep & Dayak dan Islam & Dayak dan kristen \\
\hline Kepulauan Riau & Ismeth Abdullah & Melayu dan Islam & Keturunan Arab dan Islam \\
\hline
\end{tabular}

(Sumber: diidentifikasi berdasarkan beragam publikasi media massa)

mempunyai ciri kesamaan biologis seperti wajah, warna kulit, serta ciri-ciri biologis lainnya. Dari perspektif sosial, etnisitas merupakan suatu komunitas yang mempunyai kesamaan tingkah laku sosial baik yang terikat karena hubungan biologis maupun ikatan-ikatan sosial lainnya. Dari perspektif antropologis, komunitas manusia dapat dilihat dari budaya yang dimilikinya. Dalam perspektif politik, etnisitas berkaitan dengan nasionalisme, yang saling mempengaruhi satu dengan yang lainnya.

Etnisitas berasal dari kata etnis atau dalam budaya dan bahasa Yunani kuno disebut dengan ethnos yang menunjukkan suatu yang sinonim dengan konsep manusia beradab, yaitu komunitas masyarakat pemeluk agama baik non-Kristiani maupun non Yahudi. Compliance gaining adalah upaya yang

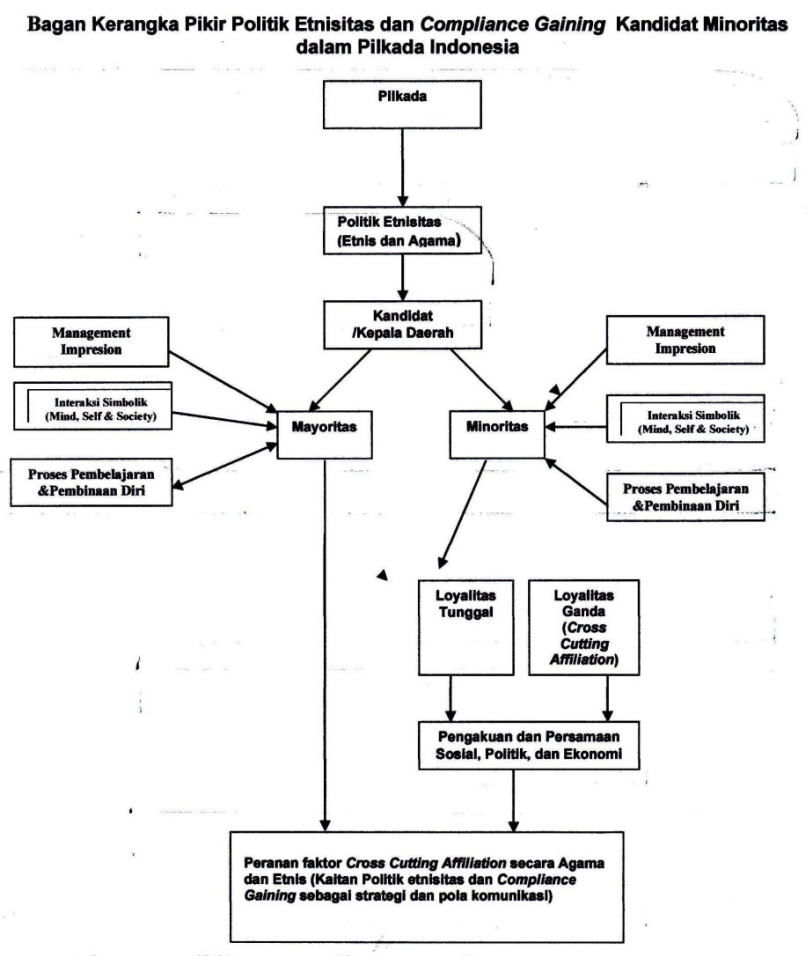

dilakukan agar orang lain melakukan apa yang kita inginkan atau agar orang lain menghentikan pekerjaan yang tidak kita sukai. Upaya orang lain mematuhi apa yang kita inginkan merupakan tujuan komunikasi yang paling umum dan paling sering digunakan. Pesan-pesan yang dikonstrusikan agar orang memiliki kepatuhan dan bertindak sesuai dengan apa yang diinginkan komunikator.

\section{METODE PENELITIAN}

Penelitian ini menggunakan paradigma konstruktivis untuk memaparkan suatu realitas yang terjadi selama Pilkada berlangsung, termasuk sebelum dan sesudahnya. Pendekatan kualitatif untuk mendeskripsikan cross cutting affiliation secara agama dan etnis sebagai bagian dari politik etnisitas dan compliance gaining dalam pola dan strategi komunikasi yang dilakukan oleh pasangan kandidat terpilih pada Pilkada di Kalimantan Barat (CornelisChristiandy Sanjaya) selama kampanye berlangsung. Lebih khusus lagi, penelitian ini juga berupaya menjelaskan tentang peranan faktor cross cutting affiliation atau loyalitas ganda yang dimiliki seorang kandidat untuk memenangkan Pilkada.

Unit analisisnya adalah individu, yaitu pasangan Gubernur dan Wakil Gubernur Kalimantan Barat yang terpilih (Cornelis-Cristiandy). Oleh karena Pilkada Kalimantan Barat telah dilangsungkan 15 November 2007, maka sifat studi ini adalah meneliti keadaan yang telah lalu (post puctum). Untuk mengetahui peristiwa apa saja yang terjadi sebelum, di saat dan sesudah proses Pilkada tersebut berlangsung, peneliti menelusuri pemberitaan di berbagai media cetak (Pontianak Post, Borneo Tribun, Equator, Berkat dan Kalimantan Review) dan media elektronik (TVRI Kalbar) serta dari pelaku yang terlibat dalam Pilkada tersebut, baik 
dari golongan masyarakat maupun partai politik. Teknik Pengumpulan Data dilakukan melalui Studi Literatur, Observasi Berpartisipasi, Wawancara Mendalam.

\section{HASIL PENELITIAN}

\section{Cross Cutting Affiliation secara Agama}

Perolehan suara Cornelis-Christiandy mencapai 43,67\% (930.679 suara dari 2.131.089 suara sah). Pasangan nomor urut 4 ini menang di beberapa Kabupaten/Kota yakni Kabupaten Landak, Sanggau,
Kapuas Hulu, Singkawang, Bengkayang, Melawi, Sintang dan Sekadau. Rival terberatnya Usman Jafar dan L.H Kadir dengan nomor urut 1 unggul di tiga Kabupaten/Kota yaitu: Sambas, Pontianak dan Kota Pontianak. Nomor urut 2 H. Oesman Sapta-Drs. Ignatius Lyong unggul di Ketapang. Pasangan urut 3 Akil Mochtar-A.R Mecer tidak memiliki suara dominan pada masing-masing kabupaten/kota. Selengkapnya peta wilayah kemenangan masingmasing kandidat di kabupaten/kota tersebut beserta persentase agama penduduknya dapat dilihat dalam tabel berikut.

Tabel 6.2 Peta Wilayah Kemenangan Cornelis-Christiandy dan Kandidat Lainnya berdasarkan

Agama Penduduknya

\begin{tabular}{|c|c|c|}
\hline Pasangan Kandidat dan Nomor Urut & Wilayah Kemenangan & Komposisi Agama \\
\hline \multirow[t]{5}{*}{ Cornelis - Chriatiandy Sanjaya (No.4) } & 1. Landak & $\begin{array}{l}\text { Istam }(16,18 \%) \text {; Katolik }(26,79 \%) \text {; } \\
\text { Protestan }(58,25 \%) \text {; Budha }(0,041 \%) \text {; } \\
\text { Mindhu }(0,004 \%) \text { : Lainmya } \\
(0,032 \%) \text {. }\end{array}$ \\
\hline & 2. Sanggau & $\begin{array}{l}\text { Protestan }(14,76 \%) \text { : Budha } \\
(0,004 \%) \text {; Hindhu }(-\%) \text {; Lainnya } \\
(0,07 \%) \text {. }\end{array}$ \\
\hline & 3. Kapuas Hulu & $\begin{array}{l}\text { Isiam }(58,32 \%) \text {; Katolik }(30,64 \%) \text {; } \\
\text { Protestan }(10,72 \%) \text {; Budha }(0,012 \%) \text {; } \\
\text { Hindhu }(0,006 \%) \text {; Lainnya }(0,013 \%) \text {. }\end{array}$ \\
\hline & 4. Singkiawang & $\begin{array}{l}\text { Islam }(41,57 \%) \text {; Katolik }(0,85 \%) \text {; } \\
\text { Protestan }(0,64 \%) \text {; Budha }(40,33 \%) \text {; } \\
\text { Hindhu }(0,054 \%) \text {; Lainnya }(0,27 \%) \text {. }\end{array}$ \\
\hline & 5. Bengkayang & $\begin{array}{l}\text { Istam }(33,65 \%) \text {; Katolik }(33,60 \%) \text {; } \\
\text { Protestan }(24,71 \%) \text {; Budha }(0,78 \%) \text {; } \\
\text { Hindhu }(0,02 \%) \text {; Lalnna }(0,026 \%) \text {. }\end{array}$ \\
\hline * & 6. Melawi & $\begin{array}{l}\text { Islam }(48,78 \%) \text { : Katolik }(25,75 \%) \text {; } \\
\text { Protestan }(24,63 \%) \text { : Budha }(0,02 \%) \text {; }\end{array}$ \\
\hline & 7. Sintang & $\begin{array}{l}\text { Ialam }(44,61 \%) \text {; Katolik }(30,69 \%) \text {; } \\
\text { Protestan }(21,91 \%) \text {; Budha }(0,26 \%) \text {; }\end{array}$ \\
\hline$\cdots$ & 8. Sekadau & $\begin{array}{l}\text { Isiam }(37,19 \%) \text {; Katolik }(51,01 \%) \text {; } \\
\text { Protestan }(10,24 \%) \text {; Budha }(0,52 \%) \text {; } \\
\text { Hindhu }(0,04 \%) \text { : Lainnya }(0,10 \%) \text {. }\end{array}$ \\
\hline Usman Jafar - L.H Kadir (No.1) & 1. Sambas & $\begin{array}{l}\text { Islam }(05,0 \%) \text {; Katolik }(0,25 \%) \text {; } \\
\text { Protestan }(0,35 \%) \text {; Budha }(0,90 \%) \text { : } \\
\text { Hindhu }(0,001 \%) \text { : Lainmya }(0,01 \%) \text {. }\end{array}$ \\
\hline \multirow[t]{2}{*}{ 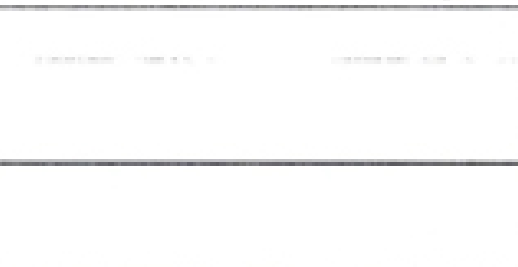 } & 2. Pontianak & $\begin{array}{l}\text { Isilam }(75.30 \%) \text { : Katolik }(0.79 \%) \text { : } \\
\text { Protestan }(0.67 \%) \text { : Budha }(0.97 \%) \text { : } \\
\text { Hindhu }(0.024 \%) \text { : Lainnya }(0.009 \%) \text {. }\end{array}$ \\
\hline & 3. Kota Pontianak & $\begin{array}{l}\text { Islam }(60,46 \%) \text {; Katolik }(18,76 \%) \text {; } \\
\text { Protestan }(0,69 \%) \text {; Budha }(0,06 \%) \text {; } \\
\text { Hindhu }(0,07 \%) \text { : Lainnya }(0,46 \%) \text {. }\end{array}$ \\
\hline $\begin{array}{l}\text { H. Oesman Sapta- } \\
\text { Drs. Ignatius Lyong (No.3) }\end{array}$ & 1. Ketapang & $\begin{array}{l}\text { Isiam }(08,46 \%) \text { : Katolik }(18.76 \%) \text { : } \\
\text { Protestan }(0,69 \%) \text { : Budha }(0,06 \%) \text { : } \\
\text { Hindhu }(0,07 \%) \text { : Lainmya }(0,46 \%) \text {. }\end{array}$ \\
\hline
\end{tabular}

Keterangan tanda (-) menunjukkan persentase pemeluknya yang sangat kecil

Sumber: Persentase pemeluk agama diperoleh dengan cara membandingkan jumlah pemeluk masing-masing agama dengan jumlah total penduduk di tiap-tiap kabupaten Kota (diolah dari Data BPS Kalbar tentang Jumlah Pemeluk Agama Menurut Golongan Agama dan Kabupaten/Kota tahun 2006) 

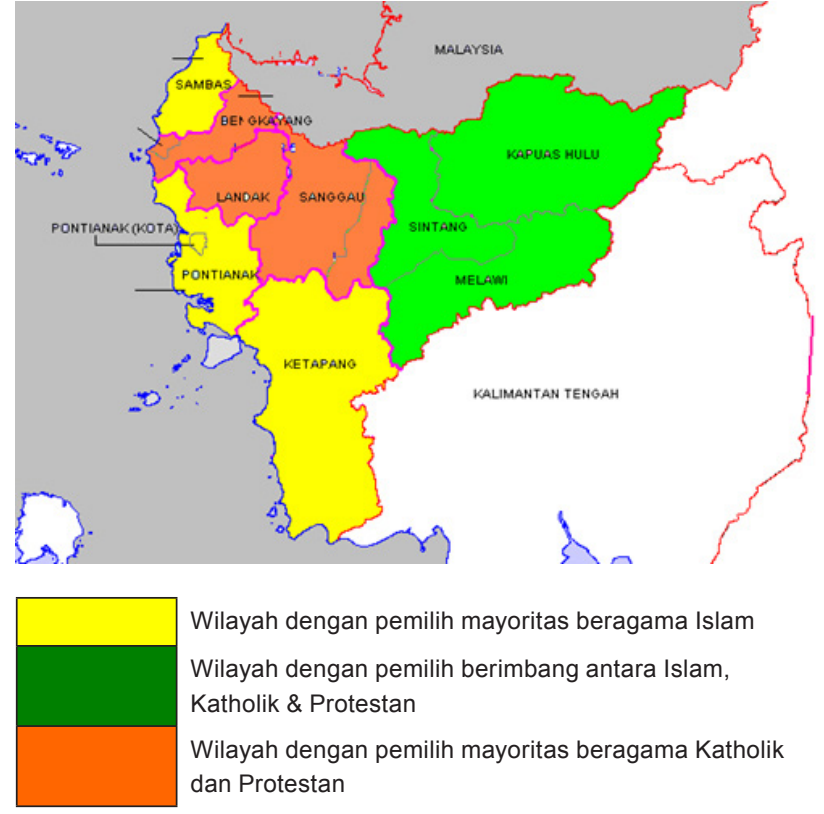

Dengan peta kemenangan tersebut dapat ditarik suatu kesimpulan bahwa agama berperan banyak dalam meraih dukungan suara. Di Kabupaten/Kota yang Islamnya lebih sedikit daripada nonmuslim (setidaknya gabungan Katolik dan Protestan) pasti mayoritas suara diberikan kepada CornelisChristiandy, misalnya di Landak, Sanggau, Bengkayang, Sekadau, Melawi, dan Sintang. Sedangkan di Singkawang kemungkinan besar dukungan suara terbesar diperoleh dari penduduk yang beragama Budha. Untuk Kapuas Hulu, perimbangan jumlah atau persentase pemeluk agama Islam dan Non Islam relatif kecil, jadi di wilayah ini faktor agama bukan menjadi faktor utama dalam meraih dukungan suara. Mungkin penyebab dukungan suara karena adanya faktor-faktor lain.

Usman Jafar-L.H Kadir unggul di wilayahwilayah yang mayoritas penduduknya beragama Islam, seperti Pontianak, Kota Pontianak, dan Sambas. Begitu pula dengan pasangan Oesman Sapta-Lyong unggul di wilayah Ketapang. Kemungkinan utama penyebab unggulnya pasangan Cornelis-Christiandy adalah dukungan suara dari mayoritas penduduknya yang non muslim. Namun perlu diketahui bahwa secara keseluruhan penduduk Kalimantan Barat yang beragama Islam 56 \%; Katolik 20\%; Protestan 13\%; Budha 7\%; Hindu dan lainnya 4\%. Dengan munculnya tiga orang kandidat Kepala Daerah yang beragama Islam bisa dipastikan bahwa dukungan suara dari pemilih yang beragama Islam terpecahpecah atau terbagi kepada ketiga kandidat Kepala
Daerah lainnya, yakni: Usman Jafar, Oesman Sapta, dan Akil Mochtar. Sedangkan total suara pemilih yang non Islam disumbangkan kepada pasangan Cornelis-Christiandy, sehingga akhirnya dapat mengantongi suara terbanyak dan mengungguli lawan lainnya.

Cornelis sadar betul bahwa salah satu faktor kemenangan dirinya ini disebabkan oleh faktor agama. Secara agama dirinya dan Christiandy adalah minoritas. Namun kombinasi keduanya dan terpecahnya dukungan suara pemilih muslim justru membuat keuntungan bagi dirinya. Cornelis mengatakan bahwa dia dan Tim Suksesnya sadar betul akan preferensi pemilih berdasarkan agama ini, namun mereka tetap melakukan pendekatan secara agama sebagai salah satu strategi kampanye dan kemenangan Pilkada.

\section{Cross Cutting Affiliation secara Etnis}

Kemenangan Cornelis-Christiandy selain ditunjang oleh faktor agama erat kaitannya juga ditunjang karena faktor etnis. Di wilayah-wilayah kemenangan Cornelis-Christiandy memang mayoritas penduduknya beretnis Dayak dan Tionghoa. Sama halnya dengan kasus faktor agama, suara pendukung yang berasal dari etnis Melayu dan etnis lainnya selain Dayak dan Tionghoa sepertinya terpecah menjadi tiga bagian suara untuk pasangan Usman Jafar-L.H Kadir, Oesman Sapta-Lyong, Akil Mochtar dan Mecer. Akan tetapi perlu diketahui bahwa ketiga kandidat Wakil Gubernur pasangan tersebut adalah beretnis Dayak. Namun pengaruh Dayak bagi kandidat Wakil Gubernur ini tidak begitu signifikan pengaruhnya. Keunggulan suara masih tetap dimenangkan oleh Cornelis-Christiandy.

Pemetaan kemenangan Cornelis-Christiandy sulit untuk ditunjukkan dengan persentase etnis penduduk karena tidak tersedianya data komposisi etnis penduduk per Kabupaten/Kota sebagaimana komposisi penduduk berdasarkan agama. Penyebabnya, bagi masyarakat Kalimantan Barat berbicara mengenai etnis adalah sesuatu yang ditabukan untuk diketahui dan sangat personal sifatnya mengingat banyaknya konflik etnis di masa lalu (sebut saja konflik Dayak dan Madura di Sambas). BPS Provinsi Kalimantan Barat juga tidak bersedia untuk memberikan keterangan tentang perimbangan komposisi etnis di Kalimantan Barat. 


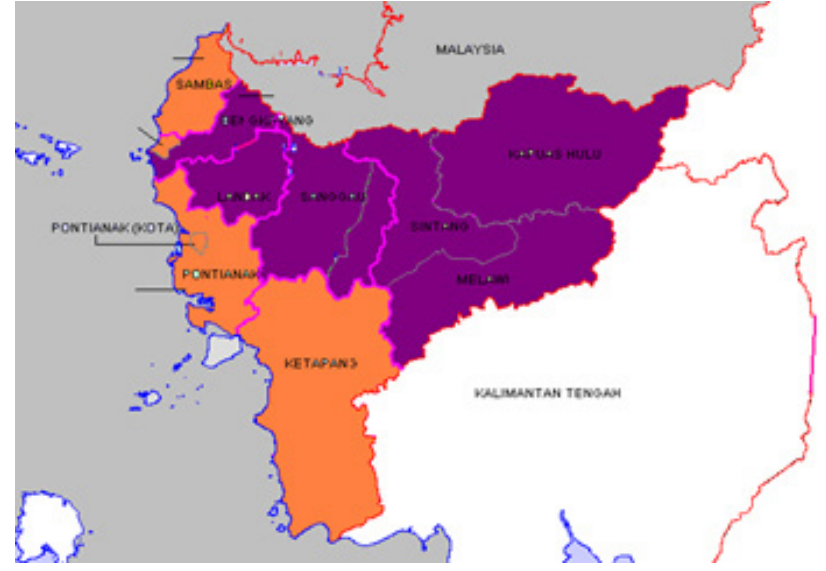

Wilayah dengan pemilih mayoritas suku Melayu

Wilayah dengan pemilih mayoritas suku Dayak
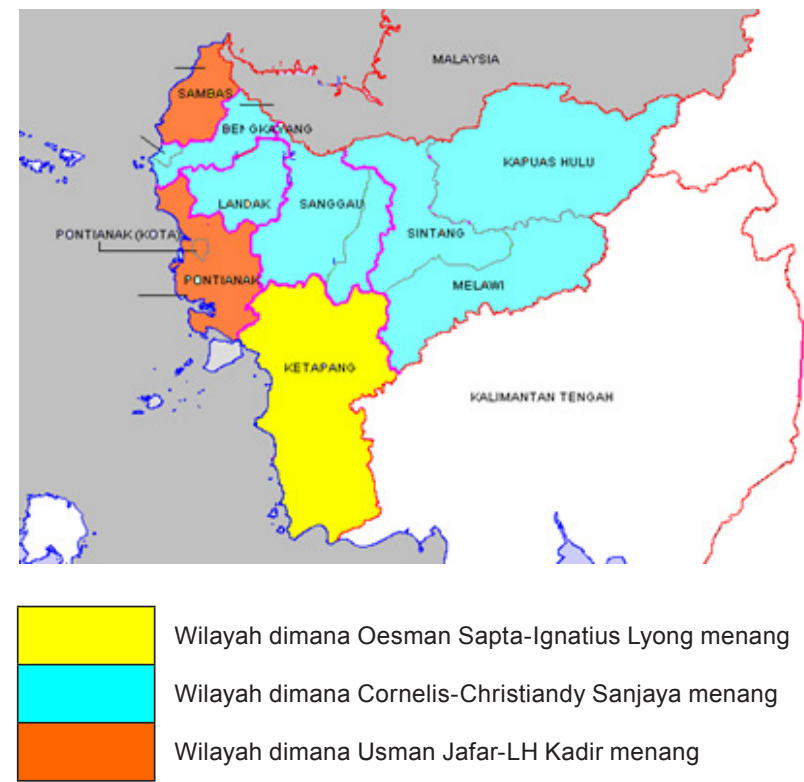

Wilayah dimana Oesman Sapta-Ignatius Lyong menang

Wilayah dimana Cornelis-Christiandy Sanjaya menang

Wilayah dimana Usman Jafar-LH Kadir menang

\section{KESIMPULAN}

Kesimpulan penelitian ini adalah: Dimensi sosial di Kalimantan Barat seringkali diwarnai dengan perpecahan dan konflik dalam catatan sejarahnya. Namun konflik tersebut tidak melebar dalam ranah politik pasca reformasi dan Pilkada. Sementara di beberapa tempat lain di Indonesia belum ada pemisahan yang jelas antara ranah sosial dan politik. Permasalahan politik selalu dicampuradukkan dengan masalah sosial dan begitu pula sebaliknya, sehingga senantiasa terlibat konflik berkepanjangan. Dari sudut pandang ini, masyarakat Kalimantan Barat yang heterogen justru cerdas dalam menangkap dan menyalurkan aspirasi politiknya.

Banyak politikus atau partai politik yang terkesan tidak tanggap dengan perubahan-perubahan di masyarakat. Dan yang lainnya menafikan kondisi masyarakat, sejarah dan pengalaman-pengalaman sosial dalam menentukan keputusan-keputusan politik. Padahal faktor sosiologis, historis dan psikologis masyarakat penting untuk di kaji lebih lanjut sebagai suatu diskusi sebelum menentukan pilihan.

Berkembangnya tehnologi dan ilmu pengetahuan modern seringkali mempercayai bahwa hitungan matematis senantiasa berhasil untuk memprediksi kemenangan kandidat. Padahal, ada hal-hal lain yang tidak dapat dicerna secara matematis. Itulah yang dimaksud dengan konteks budaya masyarakat, yang didalamnya termasuk adat istiadat, sikap pandang, tata cara, pengetahuan dan perangkat budaya lainnya.

Dalam menyetir emosi pemilihnya CornelisChristiandy menggunakan identifikasi diri berdasarkan agama, etnis serta partai pengusung. Tidak seperti saingannya yang lain yang terlihat netral dalam mempresentasikan dirinya. CornelisChristiandy justeru terang-terangnya mengeksploitasi identitas etnis yang melekat pada diri mereka. Hal ini dilakukannya dalam rangka kegiatan memobilisasi massa pendukung di beberapa daerah yang mayoritasnya beretnis Dayak dan Tionghoa seperti Singkawang. Dengan demikian dapat dikatakan pada faktor cross cutting affiliation kandidat berpengaruh.

\section{DAFTAR PUSTAKA}

Brockington, David.et.al. Minority Representation Under Cumulative and Limited Voting. The Journal of politics, 60(4), 1108-25. USA: The University of Texas Press.

Carlson, James M. (1993). The Impact Of Etnicity on Candidate Image. USA: Providence College.

Citrin, Jack.et.al. (1990). White Reaction to Black Candidates: When Daes race Matter? Chicago: The University Chicago Press.

Connaughton, Stacey, Jarvis, Sharon E. Apolitical Politics:Gop Efforts to Foster Identification From Latinos, 1984-2000. Coomunication Studies; Mei 2004; Vol. 3; Pp464-480. Academic Research Library.

Collins, William P. (1980). Race and Political Cleavage: Ten Positions in a Local Election. Sage Publication.

Eriyanto. (2008). Etnis dalam Pilkada. Jakarta: Lingkaran Survei Indonesia.

Florus, Paulus.et.al. (2005). Kebudayaan Dayak: 
Aktualisasi dan Transformasi. Pontianak: Institut Dayakologi.

Featherman, Sandra. (2001). Etnicity \& Ethnic Candidates: Vote Advantages in Local Election. Amerika: Temple University.

Hutchinson, John \& Smith, Anthony D. (1996). Ethnicity. New York: Oxford.

Jacques Bertrand. (2004). Nationalism and Ethnic Conflict in Indonesia. United Kingdom: University of Cambrige.

Kotkin, Joel. (1992). Tribes: How Race, Religion, and Identity Determine Success in the New Global Economy. New York: Random House.

Lieske, Joel. et.all. (1981). The Racial Factor in Urban Election. USA: Cleveland State University.

Mujani, Saiful. (2007). "Perilaku Pemilih Atas Partai dan Presiden".

Nasikun. (2005). Sistem Sosial Indonesia. Jakarta: Raja Grapindo Persada.

Nordholt, Schulte Henk \& Klinken, Gerry Van. (2007). Politik Lokal di Indonesia. Jakarta: Yayasan Obor Indonesia.

Kalimantan Review, Edisi 149 \& 150/XVII/ Februari/2008.

Harian Berkat, edisi 10 Oktober 2007; Edisi 15-16 Januari 2008.

Pontianak Post, 24 Oktober 2007; 1-10 November 2007. 